\title{
PHYSICAL ACTIVITY AS PREVENTION OF CHRONIC ILLNESSES IN SENIORS
}

\author{
Katarzyna Sygit, 1 , A, B Marian Sygit, 2, C, D Mariusz Pietrzak, B, E \\ 1 University of Szczecin, Faculty of Physical Education and Health Promotion, Department of Health Promotion \\ 2 University of Szczecin, Faculty of Physical Education and Health Promotion, Department of Health Education

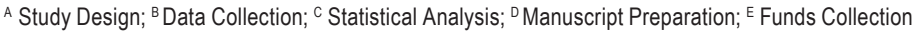 \\ Address for corpespondence: \\ Katarzyna Sygit, $\mathrm{PhD}$ \\ University of Szczecin, Faculty of Physical Culture and Health Promotion, Department of Health Promotion \\ Al. Piastów 40 b, bl.6 71-065 Szczecin, Poland \\ E-mail: ksygit@poczta.onet.pl
}

\begin{abstract}
Ahstract. Physical activity is of key importance in prevention of chronic illnesses, such as cardiovascular disease or metabolic diseases. Lack of regular workout in seniors favors the development of these diseases. It is, therefore, advisable to change one's lifestyle and engage in regular workout in order to reduce the risk of chronic illnesses and disabilities. The aim of this paper is to present how important physical activity is in prevention of chronic illnesses in seniors.
\end{abstract}

Key Worlls: physical activity, seniors, chronic illnesses

\section{Introduction}

Among seniors, 65+-year-olds are the quickest growing age group. At the same time, this particular group suffers from the highest incidence of chronic illnesses, physical disabilities and dependence on health care, although majority of these cases might be effectively prevented (Borowiak, Kostka, 2006; Kurpas, Czech, Mroczek, 2012).

Approximately $88 \%$ of $65+$-year-olds suffer from at least one chronic disease which in many cases decreases their well-being and comfort of everyday life (Makowiec-Dąbrowska, 2012). Although it has been proved that regular workout helps maintain good health and fitness, seniors tend to adopt more sedentary lifestyle over time. Majority of $65+$ Social Services patients are individuals suffering from one of chronic illnesses or disabilities (Psaltopoulou et al., 2008).

It has been shown that workout leads to lower risk of ischemic heart disease, hypertension and type 2 diabetes (Forjasz, Nowak, 2015). It is justified to believe that this relation can be extended to seniors as well. In fact, given the higher incidence of these diseases, one may expect even better results. Intolerance of workout and lack of cooperation in seniors usually stem from a misconception that chronic illnesses are an intrinsic part of the aging process. It is commonly believed that seniors' lifestyle cannot be changed, that chronic illnesses cannot be 
prevented - just as the old age is unavoidable. Many studies, however, proved that these beliefs are not grounded (Rywik et al., 2001).

Today we know that some risk factors may be decreased, i.e. they are not unavoidable, as many would argue. In order to do that, a change of lifestyle and regular workout are recommended. Physically active seniors run lower risk of disability and present lower costs of health care (Pasek, Pasek, Sieroń, 2011).

The aim of this paper is to present how important physical activity is in prevention of chronic illnesses.

\section{Workout vs cardiovascular disease}

Sedentary lifestyle is an independent risk factor of cardiovascular disease. As a result, it leads to twice as many illnesses, compared to physically active individuals. Lack of exercise is just as risky for the circulatory system as smoking 20 cigarettes per day, high cholesterol or mild hypertension. Regular workout effectively prevents hypertension, type 2 diabetes and ischemic heart disease. Moreover, exercise is related to other lifestyle changes, such as lowered body mass and generally lead to improved quality of life (Bild et al., 1993).

With age, the incidence of obesity, glucose intolerance, ischemic heart disease, hypertension and fat metabolism disorders increases. Clinical trials with young and middle-aged men showed that increased physical activity leads to lowered total cholesterol, LDL and triglyceride levels, and well as decreased blood pressure. Workout increases HDL levels and overall fitness (May at al., 2006). Unfortunately, evidence of beneficial effects of workout on seniors are much more modest. Some researchers believe that achieving similar results in seniors requires longer but less intense workout (Fiatarone, O'Neill, Doyle, 1994; Gębka, Kędziora-Kornatowska, 2012).

\section{In hypertension}

Change of lifestyle, i.e. increased physical activity and low-fat diet results in lowered tension and overall improvement of lifestyle (Knoops, de Groot, Kromhout, Perrin, 2004). It is recommended to encourage all patients to change their lifestyle, which will lead to lowered tension and decreased risk of cardiovascular diseases. If there are no additional risk factors or permanent damage to organs, patients with mild or moderate hypertension are advised to change lifestyle as the only treatment in hypertension. Thus, pharmacotherapy may be delayed for one full year. It is advisable to attempt to control hypertension by changing patient's lifestyle instead of prescribing drugs (Leveille, Guralnik, Ferrucci, Langlois, 1999).

This disease requires a careful selection of exercises (Pasek et al., 2011). It has been shown that dynamic aerobic exercises (such as marching, running) decrease tension. Static exercise, however, seems less effective, therefore individuals who do static workout should be carefully monitored. Light or moderate dynamic workout (30 minutes, at least 3 times per week) lower tension much more effectively than more intense workout. This level of physical activity is also recommended by WHO (WHO 1997). Therefore, patients should be encouraged to engage in moderate, not intense, workout. As a result of exercises, blood pressure is lowered by $5-10 \mathrm{~mm} \mathrm{Hg}$ in only 5 weeks. Moderate workout brings many health benefits, does not overstrain the patient, is safe and, most importantly - does not put off the patient, which promotes perseverance. For the beneficial effects to appear, the patient needs to exercise regularly and over a period of time. Light and moderate hypertension patients get better effects when they participate in dynamic, moderately intense workout for 60 minutes 3-4 times per week (Kurpas, Kusz, Jedynak, Mroczek, 2012). 
Hypertension patients' reaction to workout program may vary, depending on level of hypertension, medication and age. The increased by exercise Vo2 max is not always accompanied by adequately lowered tension. Individuals who take blood pressure-reducing medication should also take up exercise as an additional measure. Regular workout sometimes reduces the need for medication. Even better results may be obtained by implementing exercise and other lifestyle changes and pharmacotherapy (Bild et al., 1993).

Significant reduction of blood pressure does not require very intense exercises. Patients should not be advised to perform only isometric and weight exercises, as it is still uncertain whether they have truly beneficial effects. It is known, however, that they result in a short-term increase of systolic and diastolic pressure. Individuals with well-controlled light or moderate hypertension may use weights during exercise. Naturally, these exercises should be closely monitored and the weights should not be too heavy, while number of repetitions in a series may be increased. Seniors should not exercise in hot environments due to their inefficient thermal regulation. Moreover, patients should be made aware that hypertension medication influences central or peripheral nervous system, which may lead to physiological response of the body, e.g. slower or faster heartbeat. Some drugs, especially beta-blockers, may lead to slower heartbeat, which requires increased stroke volume to meet higher oxygen needs of the muscles at work. These drugs may, therefore, lead to lowered stamina of the patient (Kostka, Bogus, 2007).

\section{Heart failure}

Not long ago, it was still believed that physical activity is not beneficial to convalescent patients with a significant left ventricle dysfunction (Marchewka, Dąbrowski, Żołądź, 2012). Patients with heart failure were therefore advised to rest. However, since 1980s it has been believed that aerobic exercises and exercises with small weights may be beneficial. They lead to increased stamina and breathing reserve, improved blood circulation in lower limbs and mitigation of symptoms.

Intensity and duration of workout depend on the severity of symptoms. It is recommended to take breaks every 5-10 minutes to avoid patient's discouragement, tiredness, injuries and complications of the circulatory system. Patients with heart failure (as opposed to patients with other circulatory system diseases) should engage more in exercises with weights (Kostka, Lacour, Bonnefoy, 2001). Many authors believe that this type of exercise is risky as it leads to a sudden and increased oxygen consumption of the heart and higher systolic blood pressure (Korewicki, 2000; Kurpas, 2012; Papademetriou, 2005). There are no established recommendations for exercises with weights. Majority of researchers agree that patients should start with 1-3 series of 12-15 repetitions of exercises that involve large muscle groups before they add exercises involving smaller muscle groups. While lifting weights, one should avoid the Valsalva effect (Makowiec-Dąbrowska, 2012).

Patients with congestive heart failure are advised to perform interval training. It encompasses $10-20$ cycles: 30 seconds of intense aerobic exercise followed by 60 seconds of rest. Patients who have led sedentary life may at first need to reduce the 30 -second period, as it may be beyond their abilities. They should not, however, give up the weights, as they are the trigger for type 2 myofibers (Sygit, 2015).

\section{Exercise in metabolic diseases: fat metaholism disorders and diabetes}

Majority of studies devoted to impact of exercise on fat metabolism disorders focus only on age groups with highest incidence (44-55 years old; observation ends with 65-70-years-olds). There are no studies available 
devoted to individuals over 70 years of age, as well as only women. The best documented issue is the impact of exercise on HDL concertation (Kostka, Bogus, 2007).

It has been proved beyond doubt that with age glucose intolerance and incidence of type 2 diabetes increases. There is no clear evidence, however, that these phenomena are related to lack of exercise. In diabetic patients, exercise has positive impact on circular system functions and insulin sensitivity, which in turns improves metabolic control. It often helps reduce the need for oral diabetes medicine. Changing one's lifestyle, e.g. taking up regular exercise, may even prevent development of type 2 diabetes (Kurpas et al., 2012; Gębka, Kędziora-Kornatowska, 2012).

In American research, 530 subjects with glucose intolerance were divided into 4 groups. Group I did exercise, Group II went on a diet, Group III did exercise and went on diet, while Group IV was the control group with no changes to their lifestyle. During the research (2002-2004) diabetes incidence in groups I-III was lower than in Group IV. The difference was proportional to intensity of preventive measures. It may mean that the bigger changes of lifestyle, the better chance of avoiding type 2 diabetes in old age (Di Bari, van de Poll-Franse, Onder, 2004).

Workout is a very effective, additional part of treatment of type 2 diabetes, especially in seniors. However, seniors should be given detailed instructions as to how to accompany the trainings with diet, liquids, how to control sugar concentration, what shoes to wear, how to warm up and how to finish the training. Podiatrist or sports trainer's advice may be required when choosing appropriate shoes. Sugar level fluctuations during training may be avoided by consuming energy bars and drinks at particular intervals (Sumukadas, Witham, Struthers, McMurdo, 2007).

Except for patients with complications, training plan modifications are hardly ever required for type 2 diabetes patients. Patients suffering from Buerger's disease, sensory neuropathy or advanced small fiber neuropathy should work out less intensely, avoid overstaining and wear special shoes. Workout plan needs to avoid body positions which affect the autonomic nervous system (e.g. sudden strain). Diabetes patients should not exercise in extreme temperatures. Individuals with fat metabolism disorders may work out without any particular limitations. Patients with diabetes and fat metabolism disorders who exercise are often able to reduce number of drugs or dosage. There are no confirmed effects of drugs on the training results. Individuals who suffer from muscle pain due to statin-based drugs, may experience increase in their symptoms as a result of exercise, especially intense workout. In such case, lowering intensity of work-out should help; another solution would be changing the drug(s) (May et al., 2006).

\section{Exercise versus osteoarthritis}

Seniors with osteoarthritis experience reduction in pain resulting from exercise. It also improves perception, strength, agility and stamina of the body. Thus, exercise has a positive impact on functional independence of patients (Kostka, Drygas, Jegier, Zaniewicz, 2009). Until not long ago, there had been no evidence of beneficial effect of exercise on osteoarthritis. On the contrary, authors of many retrospective studies noticed adverse effect of some occupational and sports therapies on the development of osteoarthritis. However, it has been found that incorrect planning of these studies makes their results unreliable (Sygit, 2015). Those studies' conclusions rather discourage from exercise. Meanwhile, workout is recommended by the American College of Rheumatology (Leveille et al., 1999).

A study that involved a small group of subjects showed that aerobic work-out and exercises that strengthen quadriceps femoris helped avoid pain and improve patients' fitness. In randomized study by Fiatarone et al. authors showed that seniors who did weight and aerobic exercise, experienced less pain after 18 months, and their general 
fitness was better compared to subjects who did not exercise, but took part in educational classes. During the study, subjects took their previously prescribed drugs, whose dosage and number was not changed. The assessment of results did not take these drugs into consideration (Fiatarone et al., 1994).

Pain plays significant role in patient's willingness to exercise. Moreover, joint instability caused by the illness or loss of protective tonus, strength and proprioception may increase the risk of injury or force the patient to reduce intensity of the training. In such cases, one needs to consider exercises done on suspensions, stretching training or higher number of series with lower number of repetitions (Pasek et al., 2011).

Training program should include both strength-building elements, as well as exercises increasing joints' range of motion. Further joint deformation must be avoided. Forced movement of deformed joints results in increased instability and pain. A reliable overstrain symptom is pain that persists more than 2 hours after the training. Knee osteoarthritis patients are often encouraged to work out at home, using progressive anaerobic exercise with limited strain of joints, as well as exercise that increases joint mobility (Pasek et. al., 2011; Rywik et al., 2001).

\section{Exercise versus osteoporosis}

As many as $30 \%$ of women after menopause suffer from osteoporosis. Knoops et al. assessed that excess mortality in this group is caused in $20 \%$ by consequences of broken femoral neck due to osteoporosis. Cumulated life-long risk of this type of injury for 50 -year-old woman may amount to $60 \%$ (Borowiak, Kostka, 2004). The role of physical exercise in osteoporosis prevention is still argued. It has been recently stated that physical exercise helps prevent bone mass loss in lumbar spine, however, it does not affect calcium scores in the forearm and femur bone (Marchewka et al., 2012).

Incidence of broken bones in seniors has doubled in the last 30 years. Incidence of osteoporosis also increased, which translates into higher costs of health care and social services. If physical activity prevents bone mass loss, it may reduce the incidence of fractures (Psaltopoulou et al. 2008). W. Evans concluded that physical activity leads to lower risk of future fractures by $50 \%$ (Evans 1999). D. Bild et al. studied the relation between physical activity and risk of future fractures due to osteoporosis in 704 women aged $65+$. The study lasted for 7 years. Amongst very active subjects, the incidence of femoral neck fracture was $36 \%$ lower than amongst the least active individuals. There was no difference, however, in terms of broken epiphysis of radial bone and bodies of vertebrae. Authors concluded that the beneficial effect of exercise on femoral neck fracture must have more than one mechanism. Probably, the risk of femoral neck fracture among low-activity individuals is lower that among those who are not active at all (Bild et al., 1993).

\section{Prevention of seniors falling down}

For the elderly, falling down is a symptom of aging, which causes fear of injury and loosing independence. Majority of falls are caused by a combination of external and internal factors, therefore the risk of falling down should always be assessed in terms of the body and the environment.

Consequences of falling down for seniors are commonly known. Fractures of femoral neck, scull and soft tissues injuries not only cause a great deal of suffering, but also require long and costly treatment and rehabilitation. Fractured femoral neck is a special threat to patients and their families, as it results in loss of independence. Walk instability and falling down are common reasons for placing patients in nursing homes. The fear of fall itself 
is capable of limiting one's physical activity, causing social isolation, depression, weakened muscles, worsened physical fitness (Makowiec-Dąbrowska, 2012).

\section{Incidence of falls and injuries}

Falls were observed most commonly in individuals who took sedatives, those with impaired cognitive skills, walk and balance disorders, disabled due to lower limbs and foot diseases. Approximately $50 \%$ of falls may be attributed to risky activities or external factors, while only $10 \%$ to acute illnesses. As authors report, among subjects who had fell down, every fourth person suffered from severe injury, especially to soft tissue. Probability of falling down is higher for women, individuals with low body mass and with limited cognitive skills. Nursing home patients face the risk factors frequently. The incidence of falling down is three time higher than in population of seniors who live at home. Thus, it is not surprising to see that fractures due to falling down are a common problem (Tinetti, 1986).

Naturally, not all seniors are equally susceptible to falling down. According to various studies, the highest risk is faced by those individuals who often experienced injuries. Based on number and type of falls, we may select patients who need complex studies. Various disease-triggered and aging-related changes may disrupt nervous system functions: sensory, central and motor, which are essential in maintaining walk stability (Pasek et al., 2011).

Single fall does not need to prove an onset of locomotive problems. It takes many disordered functions to cause problems for seniors.

A classic medical check-up, involving an assessment of organ and system functions, usually lets the doctor determine states which hinder transmission of visual and sensory stimuli, slow central processing of information, limit motor functions and weaken fitness level.

Occupational therapist may be of great help in day-to-day life of seniors. They can teach their patients how to safely care for themselves and perform necessary actions. The doctor should know whether the patient is afraid of falling down, displays symptoms of depression or has personal problems. Environmental circumstances are just as important as clinical problems (Kurpas et al., 2012; Sygit, 2015).

\section{Conclusions}

One of the most important factors that ease the passing of time and help seniors 'age well' is regular physical exercise (Kulik, Janiszewska, Piróg, 2011). Sedentary lifestyle, common in seniors, has adverse effect on majority of systems and functions of the body, which are necessary to maintain independence in everyday life. Inactivity leads to worse functions of circular, respiratory and motor systems and results in lower fitness level. Additionally, inactivity hinders glucose and orthostatic tolerance, interferes with mineral metabolism and results in many negative changes in the human body (Makowiec-Dabrowska, 2012).

In the past decades, patients suffering from various diseases were recommended to avoid exercise. Now it is known that negative consequences of hypokinesis are usually much worse than the effects of the disease itself. Thus, physical activity may be now treated as common denominator of all preventive and rehabilitative actions, irrespectively of health and fitness levels of seniors (Marchewka et al., 2012).

Recommendations for seniors include disability prevention, as well as prevention of disease typical of seniors (osteoporosis), while they still include advice for younger generations - preventive function of physical activity against circulatory and metabolic diseases (Kulik et al., 2011). 
Regular physical activity, counteracting the effects of hypokinesis, has a number of beneficial effects for seniors. It is a universal medicine used in prevention and treatment of age-related illnesses (ischemic heart disease, hypertension, obesity, hypercholesterolemia, diabetes, osteoporosis). Physical activity leads to better insulin sensitivity, improved glucose tolerance and lower risk of developing diabetes. Regular physical activity in seniors results in lower incidence of infections and normalizes lipid values (Psaltopoulou et al., 2008; Rowe, Kahn, 1997).

\section{References}

Bild, D.E., Fitzpatrick, A., Fried, L.P., Wong, N.D., Haan, M.N., Lyles, M., Bovill, E., Polak, J.F., Schulz, R. (1993). Age-related trends in cardiovascular morbidity and physical functioning in the elderly: the Cardiovascular Health Study. J. Am. Geriatr. Soc., 41, 1047-1056.

Borowiak, E., Kostka, T. (2004). Predictors of quality of life in older people living at home and in institutions. Aging Clin. Exp. Res., 16, 212-220.

Borowiak, E., Kostka, T. (2006). Influence of chronic cardiovascular disease and hospitalisation due to this disease on quality of life of community-dwelling elderly. Qual. Life Res., 15, 1281-1289.

Di Bari, M., van de Poll-Franse, L.V., Onder, G. (2004). Antihypertensive medications and differences in muscle mass in older persons: the Health, Aging and Body Composition Study. J. Am. Geriatr. Soc., 52, 961-966.

Evans, W.J. (1999). Exercise training guidelines for the elderly. Med. Sci. Sports Exerc., 31, 12-17.

Fiatarone, M.A., O’Neill, E.F., Doyle, N. (1994). Exercise training and nutritional supplementation for physical frailty in very elderly people. N. Engl. J. Med., 330, 1769-1775.

Forjasz, J., Nowak, M.A. (2015). The physical development, eating habits, and physical activity of children attending music school. Pol. J. Sport Tourism, 22, 172-181.

Gębka, D. Kędziora-Kornatowska, K. (2012). Korzyści z treningu zdrowotnego u osób w starszym wieku. Probl. Hig. Epidemiol., 93, $256-259$.

Knoops, K.T.B., de Groot, L.G.M., Kromhout, D., Perrin, A.E. (2004). Mediterranean Diet, Lifestyle Factors, and 10-Year Mortality in Elderly European Men and Women: The HALE Project. JAMA, 292, 1433-1439.

Kostka, T., Lacour, J.-R., Bonnefoy, M. (2001). Response of blood lipids to physical exercise in elderly subjects. Prev. Cardiol., 4, 122-125, 131.

Kostka, T., Bogus, K. (2007). Independent contribution of overweight/obesity and physical inactivity to lower health-related quality of life in community-dwelling older subjects. Gerontol. Geriatr., 40, 43-51.

Kostka, T., Drygas, W., Jegier, A., Zaniewicz, D. (2009). Aerobic and anaerobic power in relation to age and physical activity in men. Int. J. Sports Med., 30, 225-230.

Korewicki, J. (2000). Heart failure in patients seeking medical help at outpatients clinics. Part I. General characteristics. Eur. J. Heart Fail., 2, 413-421.

Kulik, T.B., Janiszewska, M., Piróg, E., Pacian, A., Stefanowicz, A., Żołnierczuk-Kieliszek, D., Pacian, J. (2011). Sytuacja zdrowotna osób starszych w Polsce i innych krajach europejskich, Med. Ogólna, 17, 90-95.

Kurpas, D., Czech, T., Mroczek, B. (2012). Jakość życia pacjentów z cukrzyca - jakie znaczenie mają powikłania. Family Medicine \& Primary Care Review., 14, 177-181.

Kurpas, D., Kusz, J., Jedynak, T., Mroczek, B. (2012). Ocena podejmowania zachowań zdrowotnych w grupie pacjentów chorych przewlekle. Family Medicine \& Primary Care Review, 14, 183-185.

Leveille, S.G., Guralnik, J.M., Ferrucci, L., Langlois, J.A. (1999). Aging successfully until death in old age: opportunities for increasing active life expectancy. Am. J. Epidemiol., 149, 654-664.

Makowiec-Dąbrowska, T. (2012). Wpływ aktywności fizycznej w pracy i życiu codziennym na układ krążenia. Forum Med. Rodz., 6, 130-138.

Marchewka, A., Dąbrowski, Z., Żołądź, J. (2012). Fizjologia starzenia się. Profilaktyka i rehabilitacja, Warszawa: Wydawnictwo Naukowe PWN.

May, H.T., Muhlestein, J.B., Carlquist, J.F., Horne, B.D., Bair, T.L., Campbell, B.A., Kfoury, A.G., Lyon, A.G., Kim, H., Renlund, D.G. (2006). Relation of serum total cholesterol, C-reactive protein levels, and statin therapy to survival in heart failure. Am. J. Cardiol., 98, 653-658. 
Pasek, T., Pasek, J., Sieroń, A. (2011). Leczenie ruchem (kinezyterapia) pacjentów w podeszłym wieku, Gerontol. Pol., 19, 68-76.

Papademetriou, V. (2005). Blood pressure regulation and cognitive function: A review of the literature. Geriatrics, 60, 20-24.

Psaltopoulou, T., Kyrozis, A., Stathopoulos, P., Trichopoulos, D., Vassilopoulos, D., Trichopoulou, A. (2008). Diet, physical activity and cognitive impairment among elders: the EPIC-Greece cohort (European Prospective Investigation into Cancer and Nutrition). Public Health Nutr., 11, 1054-1062.

Rowe, J.W., Kahn, R.L. (1997). Successful aging. Gerontologist, 37, 433-440.

Rywik, S.L., Wagrowska, H., Broda, G., Sarnecka, A., Pytlak, A., Polakowska, M., Drewla, J., Korewicki, J. (2000). Heart failure in patients seeking medical help at outpatients clinics. Eur J Heart Fail., 2, 413-421.

Lee, I.-M., Skerrett, J. (2001). Physical activity and all-cause mortality: what is the dose-response relation? Med. Sci. Sports Exerc., 33, 459-471.

Sumukadas, D., Witham, M.D., Struthers, A.D., McMurdo, M.E. (2007). Effect of perindopril on physical function in elderly people with functional impairment: a randomized controlled trial. CMAJ, 177, 867-874.

Sygit, K. (2015). Fundamental significance of physical activity for seniors' health. Central European Journal of Sport Sciences and Medicine, 4, 53-59.

The WHO (1997). Guidelines for promoting physical activity among older persons. J. Aging Phys. Activity, 5, 1-8.

Tinetti, M.E. (1986). Performance-oriented assessment of mobility problems in elderly. J. Am. Geriatr. Soc., 34, 119-126.

Cite this article aS: Sygit, K., Sygit, M., Pietrzak, M. (2016). Physical Activity as Prevention of Chronic Illnesses in Seniors. Central European Journal of Sport Sciences and Medicine, 14 (2), 79-86. DOI: 10.18276/cej.2016.2-09. 